\title{
PreVAlence of adHeRence to PhaRmacological TREATMENT IN PATIENTS WITH TYPE 2 DIABETES MELLITUS
}

\footnotetext{
Clin Biomed Res. 2018;38(4):324-331

1 Faculdade de Medicina, Universidade Luterana do Brasil (ULBRA). Canoas, RS, Brasil.
}

2 Departamento de Medicina Interna, Universidade Luterana do Brasil (ULBRA). Canoas, RS, Brasil.

Corresponding author:

Camila Vicenzi

camilavicenzi93@gmail.com

Universidade Luterana do Brasil

Avenida Farroupilha, 8001.

92425-900, Canoas, RS, Brasil.

\author{
Camila Vicenzi ${ }^{1}$, Milene Moehlecke ${ }^{2}$
}

\begin{abstract}
Introduction: Evidence in the literature indicates that patients with type 2 diabetes (T2D) have a very low level of adherence to pharmacological treatment and that despite several interventions to improve it, a number of obstacles to optimal care limit the extent to which such goals can be achieved. This study attemts to assess the sociodemographic profile of patients with T2D, and to identify the main reasons for nonadherence.
\end{abstract}

Methods: This cross-sectional study evaluated patients with T2D for at least 6 months who are regularly followed at an endocrinology outpatient clinic or who have been admitted to a university hospital. Adherence was assessed by a modifed Morisky Green test and the Batalla test.

Results: Ninety-six patients were included, mostly women (59\%), white (76\%), and with mean age of $52 \pm 12$ years. Only $49 \%$ of patients adhered to drug treatment according to the Batalla test, while $24 \%$ were classifed as high adherence, $41 \%$ as moderate adherence and $34 \%$ as low adherence to drug treatment according to the modifed Morisky Green test. Considering glycated hemoglobin levels as a reference method, only $37 \%$ of patients were within the currently recommended values, with higher adherence among women compared to men (44\% vs. $23 \%, P=0.044)$.

Conclusions: The prevalence of adherence among patients with T2D was very low. Older age, insulin therapy and male sex were more strongly associated with worse adherence. The main barrier limiting treatment adherence was lack of motivation, especially due to difculties in adopting a healthy and balanced diet.

Keywords: Type 2 diabetes; adherence; chronic disease

Type 2 diabetes (T2D) comprises 90 to $95 \%$ of patients with diabetes, thus representing the most common form of the disease ${ }^{1}$. Its relevance in the current medical setting is justified by its increasing prevalence and significant morbidity and mortality. It is characterized by deficient insulin action and/or secretion, resulting in hyperglycemia and predisposition to develop multiple micro- and macrovascular complications ${ }^{2}$. Obesity, defined as body mass index (BMI) higher than or equal to $30 \mathrm{~kg} / \mathrm{m}^{2}$, is found in most patients with this form of diabetes, in addition to concomitant diseases, such as dyslipidemia and systemic arterial hypertension (SAH) ${ }^{1}$.

T2D treatment consists of lifestyle changes - a balanced diet, rich in complex carbohydrates and unsaturated fats, and physical exercise, in addition to oral hypoglycemic agents associated or not with insulin ${ }^{3}$. Despite the importance of glucose control, nonadherence to drug and non-drug treatment is quite frequent in this population, which increases the risk of complications and mortality. It is estimated that $50 \%$ of patients with chronic diseases in developed countries are nonadherent to drug therapies, and this rate is even higher in developing countries such as Brazil ${ }^{4}$.

Adherence to treatment is usually multifactorial, involving factors related to patient, healthcare provider and healthcare system ${ }^{5,6}$. Thus, several 
methods have been developed over recent decades to assess adherence to drug therapy. However, so far, there is no method that could be considered the "gold standard" to assess behavior related to adherence to drug therapy ${ }^{7,8}$.

The Morisky-Green test (MGT) is a validated questionnaire that assesses patient's attitude toward treatment $t^{9,10}$. Despite having been initially created to assess adherence within the scope of $\mathrm{SAH}$, this test has been used for assessing several chronic diseases, including diabetes ${ }^{9}$. Another common instrument is the Batalla test, which evaluates patient's level of knowledge of the disease ${ }^{11}$. In addition to indirect methods, regular monitoring of glycated hemoglobin $(\mathrm{Hb} 1 \mathrm{Ac})$ levels is another measure for adherence in DM.

Considering the prevalence of T2D as well as the socioeconomic impact of chronic complications associated with poor disease control, the purpose of this study was to evaluate the sociodemographic profile of patients with $\mathrm{T} 2 \mathrm{D}$, identifying the prevalence of adherence to pharmacological treatment as well as the major obstacles to handling such patients.

\section{METHODS}

\section{Design}

This cross-sectional study was conducted at an endocrinology outpatient clinic and at an inpatient ward of the University Hospital of Canoas, metropolitan area of Porto Alegre, southern Brazil. Patients were interviewed between March 2016 and March 2017.

\section{Patients}

Patients of both sexes, older than 18 years of age, diagnosed with T2D for at least 6 months, regularly followed at the endocrinology outpatient clinic or admitted to the hospital, were consecutively included.

Patients who refused to sign an informed consent form and patients diagnosed with other types of diabetes were excluded. This study was approved by the Ethics Committee at the University Hospital of Canoas and informed consent was obtained from all participants.

\section{Clinical and Anthropometric Measurements}

Astandard questionnaire concerning sociodemographic and clinical aspects, including comorbidities, drugs being used and method to obtain the drugs, was administered. In addition, a brief physical examination was performed to assess anthropometric measures and blood pressure.

Weight $(\mathrm{kg})$ and height $(\mathrm{cm})$ were measured with patients wearing lightweight clothes and no shoes while standing on scales with capacity for $300 \mathrm{~kg}$
(Welmy). BMI was calculated by dividing weight by squared height $\left(\mathrm{kg} / \mathrm{m}^{2}\right)$. Patients were classified as eutrophic (BMI ranging from 18.5 to $24.9 \mathrm{~kg} / \mathrm{m}^{2}$ ), overweight (BMI ranging from 25 to $29.9 \mathrm{~kg} / \mathrm{m}^{2}$ ) or obese (BMI $\left.\geq 30 \mathrm{~kg} / \mathrm{m}^{2}\right)$, according to World Health Organization criteria ${ }^{12}$. Abdominal circumference $(\mathrm{cm})$ was measured at the mid-point between the last rib and the iliac crest with a fiberglass tape measure ${ }^{13}$.

To assess blood pressure, two measures were taken, at 2-minute intervals, using a cuff suitable to arm diameter, by the oscillometric method. A patient was deemed hypertensive if mean systolic blood pressure (SBP) was greater than or equal to $140 \mathrm{mmHg}$ and/or diastolic blood pressure (DBP) was greater than or equal to $90 \mathrm{mmHg}$ on at least 2 occasions, or if the patient had had a prior event of SAH during pharmacological treatment regardless of blood pressure levels ${ }^{14}$.

\section{Biochemical Parameters}

Fasting glucose levels were determined by glucose-oxidase method; creatinine by Jaffe reaction; $\mathrm{Hb} 1 \mathrm{Ac}$ by high-performance liquid chromatography (HPLC; Merck-Hitachi 9100; reference range: 4-6\%); triglycerides and cholesterol by enzymatic method; and low-density lipoprotein (LDL) cholesterol by Friedewald equation. The Chronic Kidney Disease Epidemiology Collaboration (CKD-EPI) formula ${ }^{15}$ was used to estimate glomerular filtration rate.

\section{Assessment of Adherence}

Adherence was assessed only once and individually, prior to medical evaluation, by administering the modified MGT and the Batalla test. In the modified MGT, individuals answered yes or no to six questions. The first four questions were:

1. "Do you ever forget to take your medicine?" (0) yes ${ }^{1}$, no;

2. "Are you careless at times about taking your medicine?" (0) yes ${ }^{1}$, no;

3. "When you feel better do you sometimes stop taking your medicine?" (0) yes ${ }^{1}$, no;

4. "Sometimes if you feel worse when you take your medicine, do you stop taking it?" (0) yes ${ }^{1}$, no.

Individuals answering any of these four questions affirmatively were submitted to two additional questions:

5. "Were you informed of the importance and benefit of using your medicine?"

6. "Do you forget to get more medicines before they run out?" 
High adherence was defined as score equal to 4 points; moderate adherence as score equal to 2 or 3 points; and low adherence as score equal to 1 or 0 point. Individuals answering yes to questions 1 and/or 2 were characterized as having behavior of unintentional nonadherence, and individuals who answered yes to questions 3 and/or 4 , as having intentional nonadherence ${ }^{9}$. Individuals answering no to question 5 were considered as not realizing the importance of treatment; an affirmative answer to question 6 suggested lack of motivation as the reason for nonadherence.

In the Batalla test, treatment adherence was assessed by asking three questions about familiarity with the disease: 1) "Is T2D a lifelong disease?"; 2) "Can T2D be controlled with diet and/or drugs?"; 3) "Mention 2 or more organs affected by T2D." A wrong answer rated the patient as nonadherent ${ }^{11}$.

Adherence was assessed by considering all drugs prescribed for the patient, including those prescribed for treatment of concurrent diseases. Performance in both questionnaires was compared to $\mathrm{Hb} 1 \mathrm{Ac}$ levels, a more objective measure to monitor response to treatment.

\section{Statistical Analysis}

To calculate the sample size, it was estimated that for a $40 \%$ prevalence of nonadherence, considering $\mathrm{P}<0.05$ as statistically significant and a $90 \%$ power, 92 patients were necessary. Quantitative variables were expressed as mean \pm standard deviation (SD) or median and interquartile range, with normal and non-normal distribution, respectively. Patients were divided into two groups to analyze the results: adherent and nonadherent to drug treatment. Those who scored 4 points in the modified MGT were classified as adherent and those who scored 3 points or less, or those who gave one wrong answer in the Batalla test were classified as nonadherent. The Student's t-test for independent samples or the chi-square test was used to evaluate the association between variables and nonadherence.

A logistic regression analysis was performed to assess the predictive independent variables of adherence to pharmacological treatment, using the Batalla test or the MGT as a dependent variable, and age, sex, level of education, income, duration of T2D and insulin therapy as independent variables. The analyses were performed using the Statistical Package for the Social Science software (SPSS, version 20.0 for Windows) and $P<0.05$ was considered significant.

To analyze the performance of the Batalla and MGT questionnaires, descriptive sensitivity and specificity were measured.

\section{RESULTS}

\section{Sociodemographic Profile and Laboratory Characteristics of Patients with T2D}

Ninety-six patients were assessed. Their mean age was $52 \pm 12$ years. Most of them were women (59\%, $\mathrm{n}=57)$ and Caucasians $(76 \%, \mathrm{n}=73)$. Their mean BMI was $27 \pm 6 \mathrm{~kg} / \mathrm{m}^{2}$. Clinical and laboratory characteristics of the patients with T2D according to sex are described in Table 1. Approximately $73 \%$ $(n=67)$ of the patients were in a stable relationship. With respect to tobacco use, about $46 \%$ of the patients were current or former smokers. Most of the patients were unemployed $(71 \%)$. Their mean level of education was $6.4 \pm 3.2$ years of formal instruction, and their mean per capita income was $1,135.5 \pm 595.3$ reais (Brazilian currency). The mean use of daily medications was $5.9 \pm 2.5$ per patient - $71 \%(\mathrm{n}=69)$ took five or more medications a day while $8 \%(n=8)$ took 10 or more medications a day, and $51 \%(n=47)$ got medications only from drugstores at their Primary Health Care Units. Most patients had SAH $(87 \%, n=80)$ and were under pharmacological treatment, and $36 \%$ had abnormal blood pressure at the time of the interview.

The mean duration of T2D was $11.5 \pm 6.5$ years. With regard to disease complications, a little more than half the patients $(52 \%)$ had microvascular complications: $21 \%$ had diabetic retinopathy, $32 \%$ had diabetic neuropathy, $14 \%$ had diabetic nephropathy and $22 \%$ had more than one of these. With regard to macrovascular complications, $16 \%$ patients reported prior myocardial infarction and $7.6 \%$ reported prior cerebrovascular accident.

Regarding pharmacological treatment, $52 \%$ of patients were receiving oral therapy for T2D, $40.6 \%$ were under combined treatment (oral therapy + insulin therapy) and $7.2 \%$ were receiving only insulin therapy. Regarding laboratory tests, mean fasting glucose was $172.4 \pm 74.5 \mathrm{mg} / \mathrm{dL}$ and $\mathrm{Hb} 1 \mathrm{Ac}$ was $7.9 \pm 1.9 \%$. Regarding lipid profile, $21 \%$ of the patients had total cholesterol levels above the desired value, $28 \%$ had triglyceride levels above $150 \mathrm{mg} / \mathrm{dL}$ and $55 \%$ had HDL levels lower than the expected.

\section{Assessment of Degree of Adherence to Pharmacological Treatment \\ Batalla test}

Assessment of adherence according to clinical and laboratory variables is shown in Table 2 . With regard to assessment of adherence by the Batalla test, only $49 \%$ of the patients adhered to the treatment, with no difference between sexes $(P=0.279)$. Older age was associated with greater risk of nonadherence $(P=0.017)$. Treatment with insulin showed a tendency 
Table 1: Clinical and laboratory characteristics of patients with T2D.

\begin{tabular}{|c|c|c|c|}
\hline Clinical variables & Female & Male & $\mathbf{P}$ \\
\hline Age (years) & $64 \pm 13$ & $64 \pm 9$ & 0.852 \\
\hline Caucasians - n (\%) & $45(79 \%)$ & $27(73 \%)$ & \\
\hline Income $\left(\right.$ reais) ${ }^{*}-\mathrm{n}(\%)$ & & & 0.359 \\
\hline$<1$ & $16(28 \%)$ & $10(25 \%)$ & \\
\hline 1 to 3 & $40(70 \%)$ & $26(67 \%)$ & \\
\hline 3 to 5 & $1(2 \%)$ & $3(8 \%)$ & \\
\hline Education (years) & & & 0.553 \\
\hline 0 & $4(7 \%)$ & $1(2,5 \%)$ & \\
\hline 1 to 4 & $11(19 \%)$ & $9(23 \%)$ & \\
\hline 5 to 9 & $36(63 \%)$ & $23(59 \%)$ & \\
\hline 10 or more & $6(10 \%)$ & $6(15 \%)$ & \\
\hline Smoker (\%) & & & 0.019 \\
\hline Current & $2(3.5 \%)$ & $2(5.1 \%)$ & \\
\hline Previous & $18(31.6 \%)$ & $23(58.9 \%)$ & \\
\hline Never smoked & $37(64.9 \%)$ & $14(35.8 \%)$ & \\
\hline Body mass index $\left(\mathrm{kg} / \mathrm{m}^{2}\right)$ & $30.6 \pm 6.9$ & $28.4 \pm 5.7$ & 0.103 \\
\hline Waist circumference $(\mathrm{cm})$ & $101.3 \pm 12.4$ & $97.5 \pm 18.2$ & 0.376 \\
\hline T2D duration (years) & $11.6 \pm 7.9$ & $11.4 \pm 9.5$ & 0.940 \\
\hline Insulin therapy - n (\%) & $29(51 \%)$ & $21(54 \%)$ & 0.469 \\
\hline $\mathrm{SBP}(\mathrm{mmHg})$ & $130.4 \pm 16.7$ & $134.3 \pm 13.9$ & 0.229 \\
\hline $\mathrm{DBP}(\mathrm{mmHg})$ & $82.8 \pm 10.1$ & $85.0 \pm 8.8$ & 0.295 \\
\hline \multicolumn{4}{|l|}{ Laboratory variables } \\
\hline Fasting glucose (mg/dL) & $159.8 \pm 62.2$ & $190.5 \pm 87.0$ & 0.140 \\
\hline $\mathrm{Hb} 1 \mathrm{Ac}(\%)$ & $7.5 \pm 1.7$ & $8.5 \pm 2,0$ & 0.025 \\
\hline Total cholesterol (mg/dL) & $183.0 \pm 63.7$ & $160.9 \pm 42.3$ & 0.115 \\
\hline $\mathrm{HDL}(\mathrm{mg} / \mathrm{dL})$ & $38.2 \pm 15.9$ & $36.1 \pm 8.7$ & 0.510 \\
\hline Triglycerides (mg/dL) & $180.0(42-598)$ & $136.0(47-262)$ & 0.037 \\
\hline LDL (mg/dL) & $106.2 \pm 51.2$ & $97.2 \pm 37.6$ & 0.456 \\
\hline Creatinine (mg/dL) & $1.1 \pm 0.7$ & $1.3 \pm 1.1$ & 0.349 \\
\hline GFR - CKD-EPI (mL/min/1.73 $\left.\mathrm{m}^{2}\right)$ & $65.3 \pm 28.8$ & $73.4 \pm 28.7$ & 0.213 \\
\hline
\end{tabular}

SBP, systolic blood pressure; DBP, diastolic blood pressure; Hb1Ac, glycated hemoglobin; HDL, high-density lipoprotein; LDL, low-density lipoprotein; GFR - CKD-EPI, glomerular filtration rate - Chronic Kidney Disease Epidemiology Collaboration; *Income according to minimum wage in Brazil; T2D - type 2 diabetes.

to worse adherence $(P=0.052)$. With regard to laboratory variables, patients with higher adherence had both higher fasting glucose and higher $\mathrm{Hb} 1 \mathrm{Ac}$ levels $(P=0.037$ and 0.003 , respectively) than those with lower adherence.

Among all patients, $51 \%(n=47)$ were not able to mention at least two organs affected by T2D. A logistic regression analysis was conducted to assess predictive independent variables of adherence to pharmacological treatment, using the Batalla test as a dependent variable. The overall success rate (accuracy) of the test was $69.6 \%$, with $77.8 \%$ specificity and $57.9 \%$ sensitivity. Of all variables tested in the model (age, sex, level of education, income, duration of T2D and insulin therapy), only insulin therapy was associated with worse adherence $(\beta=-0.422, P=0.044)$.

\section{Morisky-Green Test (MGT)}

Concerning assessment of adherence by the MGT, $24 \%(n=23)$ of the patients were classified as high adherence, $41 \%(n=40)$ as mean adherence and $34 \%(n=33)$ as low adherence. Table 3 shows the percentage of negative answers (higher adherence) for each question of the test.

Among the patients classified as nonadherent (mean or low adherence), $70 \%$ were classified as unintentional, $37 \%$ as intentional and $33 \%$ as both, as described in Table 4. Furthermore, lack of motivation was found to be more prevalent as a cause of nonadherence than lack of familiarity with importance of treatment, with $57 \%$ and $28 \%$, respectively.

Assessment of adherence by the MGT is shown in Table 5. All clinical and laboratory variables were similar among patients with and without adherence, 
Table 2: Clinical and laboratory variables associated with adherence to treatment in patients with T2D according to the Batalla Test.

\begin{tabular}{|c|c|c|c|}
\hline Batalla Test & Adherence & Nonadherence & $\mathbf{P}^{*}$ \\
\hline \multicolumn{4}{|l|}{ Clinical variables } \\
\hline Sex & & & 0.279 \\
\hline Female & $26(45 \%)$ & $31(55 \%)$ & \\
\hline Male & $21(54 \%)$ & $18(46 \%)$ & \\
\hline Age (years) & $61.1 \pm 10.5$ & $66.6 \pm 11.9$ & 0.017 \\
\hline Income (reais) & $1210 \pm 660$ & $1064 \pm 522$ & 0.233 \\
\hline Years of education & $6.7 \pm 2.9$ & $6.1 \pm 3.5$ & 0.452 \\
\hline T2D (years) & $13.1 \pm 9.3$ & $10.0 \pm 7.5$ & 0.071 \\
\hline Insulin therapy - n (\%) & $20(40 \%)$ & $30(60 \%)$ & 0.052 \\
\hline Body mass index $\left(\mathrm{kg} / \mathrm{m}^{2}\right)$ & $30.0 \pm 5.5$ & $29.5 \pm 7.5$ & 0.720 \\
\hline $\mathrm{SBP}(\mathrm{mmHg})$ & $133 \pm 14$ & $131 \pm 17$ & 0.477 \\
\hline $\mathrm{DBP}(\mathrm{mmHg})$ & $85 \pm 8$ & $82 \pm 10$ & 0.118 \\
\hline \multicolumn{4}{|l|}{ Laboratory variables } \\
\hline Fasting glucose (mg/dL) & $159 \pm 54$ & $148 \pm 48$ & 0.037 \\
\hline $\mathrm{Hb} 1 \mathrm{Ac}(\%)$ & $8.6 \pm 2.0$ & $7.3 \pm 1.5$ & 0.003 \\
\hline $\mathrm{TC}(\mathrm{mg} / \mathrm{dL})$ & $178 \pm 48$ & $170 \pm 67$ & 0.609 \\
\hline HDL (mg/dL) & $35 \pm 12$ & $39 \pm 14$ & 0.239 \\
\hline Triglycerides (mg/dL) & $160(47-598)$ & $135(42-400)$ & 0.096 \\
\hline LDL (mg/dL) & $103 \pm 39$ & $100 \pm 52$ & 0.768 \\
\hline Creatinine (mg/dL) & $1.1 \pm 0.9$ & $1.3 \pm 0.9$ & 0.672 \\
\hline GFR - CKD-EPI (mL/min/1.73 $\left.\mathrm{m}^{2}\right)$ & $72.5 \pm 26.0$ & $65.4 \pm 30.9$ & 0.268 \\
\hline
\end{tabular}

SBP, systolic blood pressure; DBP, diastolic blood pressure; Hb1Ac, glycated hemoglobin; TC, total cholesterol; HDL, high-density lipoprotein; LDL, low-density lipoprotein; GFR - CKD-EPI, glomerular filtration rate - Chronic Kidney Disease Epidemiology Collaboration; ${ }^{*} \mathrm{P}<0.05$ was considered significant; Data are presented as mean \pm SD or median (interquartile range); T2D - type 2 diabetes.

Table 3: Assessment of adherence to pharmacological treatment according to the Morisky-Green test.

\begin{tabular}{lc}
\hline \multicolumn{1}{c}{ Questions } & n (\%)* \\
\hline Do you ever forget to take your medicine?" & $35(36 \%)$ \\
Are you careless at times about taking your medicine? & $35(36 \%)$ \\
When you feel better do you sometimes stop taking your medicine? & $63(65 \%)$ \\
Sometimes if you feel worse when you take your medicine, do you stop taking it? & $65(67.7 \%)$ \\
\hline
\end{tabular}

*Negative answers mean greater compliance.

Table 4: Data on nonadherence according to the Morisky-Green test.

\begin{tabular}{cc}
\hline Type & $\mathbf{n ~ ( \% )}$ \\
\hline Unintentional & $67(70 \%)$ \\
Intentional & $35(37 \%)$ \\
Both & $22(23 \%)$ \\
\hline Reason & $\mathbf{n ~ ( \% )}$ \\
\hline Lack of knowledge & $27(28 \%)$ \\
Lack of motivation & $55(57 \%)$ \\
Lack of knowledge and motivation & $26(27 \%)$ \\
\hline
\end{tabular}

except for lower total cholesterol levels in patients with higher adherence $(P=0.036)$.

Most patients (67\%) answered that their main difficulty during treatment is adopting a diet. Approximately one third $(n=25)$ of the patients answered physical exercise as the main challenge, $6 \%$ answered insulin application and another $6 \%$ answered that they do not take the prescribed drugs, either because they forget or because of the large number of drugs they should take.

The overall success rate (accuracy) of the test was $71.7 \%$, with $14.3 \%$ specificity and $96.7 \%$ sensitivity. No variable tested in the logistic regression model (age, sex, level of education, income, duration of T2D and insulin therapy) predicted worse adherence to pharmacological treatment.

\section{Glycated hemoglobin ( $\mathrm{Hb} 1 \mathrm{Ac})$ as a reference method}

Considering $\mathrm{Hb} 1 \mathrm{Ac}$ levels lower than or equal to $7 \%$ as optimal for glucose control, only $37 \%(n=31)$ of the patients were within the current recommendation, with predominance of women compared to men 
Table 5: Clinical and laboratory variables associated with adherence to pharmacological treatment in patients with T2D according to the modified Morisky-Green test.

\begin{tabular}{|c|c|c|c|}
\hline & Adherence & Nonadherence & $\mathbf{P}^{*}$ \\
\hline \multicolumn{4}{|l|}{ Clinical variables } \\
\hline Sex & & & 0.343 \\
\hline Female & $15(26 \%)$ & $42(74 \%)$ & \\
\hline Male & $8(20 \%)$ & $31(80 \%)$ & \\
\hline Age (years) & $65.7 \pm 11.8$ & $63.3 \pm 11.5$ & 0.389 \\
\hline Income (reais) & $1066 \pm 386$ & $1157 \pm 648$ & 0.524 \\
\hline T2D duration (years) & $13.8 \pm 9.8$ & $10.8 \pm 8.0$ & 0.135 \\
\hline Insulin therapy - n (\%) & $9(18 \%)$ & $41(82 \%)$ & 0.118 \\
\hline Body mass index $\left(\mathrm{kg} / \mathrm{m}^{2}\right)$ & $29.4 \pm 5.0$ & $29.8 \pm 7.0$ & 0.767 \\
\hline $\mathrm{SBP}(\mathrm{mmHg})$ & $133 \pm 14$ & $132 \pm 16$ & 0.838 \\
\hline $\mathrm{DBP}(\mathrm{mmHg})$ & $82 \pm 8$ & $84 \pm 9$ & 0.517 \\
\hline \multicolumn{4}{|l|}{ Laboratory variables } \\
\hline Fasting glucose (mg/dL) & $144 \pm 46$ & $156 \pm 52$ & 0.399 \\
\hline $\mathrm{Hb} 1 \mathrm{Ac}(\%)$ & $7.7 \pm 1.8$ & $7.9 \pm 1.8$ & 0.618 \\
\hline $\mathrm{TC}(\mathrm{mg} / \mathrm{dL})$ & $145 \pm 46$ & $182 \pm 56$ & 0.036 \\
\hline $\mathrm{HDL}(\mathrm{mg} / \mathrm{dL})$ & $33 \pm 15$ & $38 \pm 12$ & 0.234 \\
\hline Triglycerides (mg/dL) & $138(42-485)$ & $140(47-598)$ & 0.894 \\
\hline LDL (mg/dL) & $83 \pm 36$ & $107 \pm 47$ & 0.088 \\
\hline Creatinine (mg/dL) & $1.2 \pm 0.9$ & $1.2 \pm 0.9$ & 0.976 \\
\hline GFR - CKD-EPI & $69.9 \pm 33.3$ & $65.6 \pm 31.2$ & 0.753 \\
\hline
\end{tabular}

SBP, systolic blood pressure; DBP, diastolic blood pressure; Hb1Ac, glycated hemoglobin; TC, total cholesterol; HDL, high-density lipoprotein; LDL, low-density lipoprotein; GFR - CKD-EPI, glomerular filtration rate - Chronic Kidney Disease Epidemiology Collaboration; ${ }^{*} \mathrm{P}<0.05$ was considered significant.

(44\% vs. $23 \%$, respectively; $P=0.044)$. The remaining clinical and laboratory variables tested were not associated with better glucose control.

\section{DISCUSSION}

Based on the results found in this study, we are able to conclude that most patients with T2D treated at our hospital were overweight, women, Caucasians, with low level of education and monthly income a little higher than one minimum wage. Additionally, most of them had chronic complications of T2D and were taking multiple drugs on a daily basis, with complex therapeutic regimens, which encourages pharmacological nonadherence. In addition, most of the patients had fasting glucose and $\mathrm{Hb} 1 \mathrm{Ac}$ values above the desired levels.

According to the results of the Batalla test, less than half the patients showed adherence to drug treatment. Insulin therapy was associated with poor adherence to pharmacological treatment, similar to findings described in previous studies ${ }^{16,17}$. Nam et al., in their review of barriers to DM treatment, showed that patients who need insulin therapy tend to find adherence to treatment more difficult ${ }^{17}$.

According to the results of the MGT, in turn, only approximately one fifth of the patients adhered to the drug treatment proposed. A cross-sectional Brazilian study assessing treatment adherence in 54 diabetic patients found that, according to the answers to the MGT questions, only $33 \%$ of the patients were considered adherent to therapy, a similar result to that found in our study ${ }^{18}$. Also, the MGT questionnaire seems to be more reliable when a patient reports not taking the drugs, i.e., it shows a high negative predictive value. Similar results were described by Silvestre-Busto et al. in a cross-sectional study performed in Spain including 2,244 patients. It showed that those who reported being nonadherent in the MGT were telling the truth $^{19}$.

Comparing the two tests, we observed that the MGT seems more sensitive to detect nonadherent patients and is more accurate than the Batalla test. Thus, we believe that MGT is a better option to measure treatment adherence.

In general, we found a low prevalence of adherence to drug treatment in patients with $\mathrm{T} 2 \mathrm{D}$, when $\mathrm{Hb} 1 \mathrm{Ac}$ was used as a reference method. Female sex was associated with a higher probability of adherence. This was also described by Gorter et al. in a cross-sectional study of 1,029 patients who were asked about their goals and responsibilities regarding DM. The results showed greater concern with health among women compared to men, as women showed more interest and sought 
more care ${ }^{20}$. We also noted that, despite evidence of the importance of doing exercise and adopting a healthy diet, most patients still find it difficult to carry out such activities, as two thirds claimed that diet was the main obstacle for treatment, while almost one third said that it was physical exercise.

Our study has some limitations that should be considered when interpreting the main results. This is a cross-sectional study, a design that does not allow inferring causality. Additionally, the performance of the Batalla test may have been compromised in inpatients due to T2D complications, as nonadherent patients showed better glucose control than adherent patients. The reason is that many of those who were able to mention at least two organs compromised by diabetes had an acute complication (memory bias).

\section{CONCLUSION}

The results obtained in this study allow us to conclude that there is very low adherence to pharmacological treatment among patients with T2D.
Male sex, using $\mathrm{Hb} 1 \mathrm{Ac}$ levels as a direct method to evaluate glucose control and older age, considering the Batalla test, were more strongly associated with worse adherence. In addition, insulin therapy as evaluated by the Batalla test showed a tendency to worse adherence. The main barrier limiting the treatment of nonadherent patients was lack of motivation, especially due to difficulties in adopting a healthy and balanced diet. Regarding the use of indirect methods to assess adherence, the MGT showed higher sensitivity and negative predictive value compared to the Batalla test, thus being a better option to measure treatment adherence.

\section{Funding}

This work was sponsored by the main researcher.

\section{Conflicts of Interest}

The authors declare no conflicts of interest.

\section{REFERENCES}

1. Diretrizes da Sociedade Brasileira de Diabetes 2017-2018. Disponível em URL: https://www.diabetes.org.br/ profissionais/images/2017/diretrizes/ diretrizes-sbd-2017-2018.pdf

2. Scheffel RS, Bortolanza D, Weber CS, Costa LA, Canani LH, Santos $\mathrm{KG}$, et al. Prevalence of micro and macroangiopatic chronic complications and their risk factors in the care of out patients with type 2 diabetes mellitus. Rev Assoc Med Bras. 2004;50(3):2637. http://dx.doi.org/10.1590/ s0104-42302004000300031. PMid:15499476.

3. American Diabetes Association. 1. Promoting health and reducing disparities in populations. Diabetes Care. 2017;40(Suppl 1):S6-10. http:// dx.doi.org/10.2337/dc17-S004. PMid:27979888.

4. World Health Organization. 2003. Disponível em URL: https://www. who.int/chp/knowledge/publications/ adherence_full_report.pdf

5. Faria HTG, Rodrigues FFL, Zanetti ML, Araújo MFM, Damasceno MMC. Fatores associados à adesão ao tratamento de pacientes com diabetes mellitus. Acta Paul Enferm. 2013;26(3):231-7. http://dx.doi.org/10.1590/S010321002013000300005.
6. Nam S, Chesla C, Stotts NA, Kroon L, Janson SL. Barriers to diabetes management: patient and provider factors. Diabetes Res Clin Pract. 2011;93(1):1-9. http://dx.doi. org/10.1016/j.diabres.2011.02.002. PMid:21382643.

7. Brawley LR, Culos-Reed SN. Studying adherence to therapeutic regimens: overview, theories, recommendations. Control Clin Trials. 2000;21(5 Suppl):156S-63S. http://dx.doi. org/10.1016/S0197-2456(00)00073-8. PMid:11018570.

8. Cramer JA, Mattson RH, Prevey ML, Scheyer RD, Ouellette VL. How often is medication taken as prescribed? A novel assessment technique. JAMA. 1989;261(22):32737. http://dx.doi.org/10.1001/ jama.1989.03420220087032. PMid:2716163.

9. Ben AJ, Neumann CR, Mengue SS. The Brief Medication Questionnaire and Morisky-Green test to evaluate medication adherence. Rev Saude Publica. 2012;46(2):27989. http://dx.doi.org/10.1590/ S0034-89102012005000013. PMid:22331180.

10. Sewitch MJ, Abrahamowicz M, Barkun A, Bitton A, Wild GE, Cohen A, et al. Patient nonadherence to medication in inflammatory bowel disease. Am J Gastroenterol. 2003;98(7):153544. http://dx.doi.org/10.1111/j.15720241.2003.07522.x. PMid:12873575.

11. Batalla Martínez C. Cumplimiento terapéutico e hipertensión arterial. Aten Primaria. 2004;34(08):397-8. PMid:15546535.

12. World Health Organization. Obesity: preventing and managing the global epidemic. Report of a World Health Organization Consultation. Geneva: World Health Organization. 2000:256. WHO Obesity Technical Report Series, n. 284

13. Picon PX, Leitão CB, Gerchman F, Azevedo MJ, Silveiro SP, Gross $\mathrm{JL}$, et al. Medida da cintura e razão cintura/quadril e identificação de situações de risco cardiovascular: estudo multicêntrico em pacientes com diabetes melito tipo 2. Arq Bras Endocrinol Metabol. 2007;51(3):4439. http://dx.doi.org/10.1590/ S0004-27302007000300013. PMid:17546244.

14. Chobanian AV, Bakris GL, Black HR, Cushman WC, Green LA, Izzo JL JR, et al, The Seventh Report of the Joint National Committee on Prevention, Detection, Evaluation, and Treatment of High Blood Pressure: the JNC 7 
Report. JAMA. 2003;289(19):256072. http://dx.doi.org/10.1001/ jama.289.19.2560. PMid:12748199.

15. Levey AS, Stevens LA. Estimating GFR using the CKD Epidemiology Collaboration (CKD-EPI) creatinine equation: more accurate GFR estimates, lower CKD prevalence estimates, and better risk predictions. Am J Kidney Dis. 2010;55(4):6227. http://dx.doi.org/10.1053/j. ajkd.2010.02.337. PMid:20338463.

16. Bonardi G, Souza VB, Moraes JF. Funcional incapacity and the aged: a challange to health cara professionals. Sci Med. 2007;17(3):138-44.
17. Nam S, Chesla C, Stotts NA, Kroon L, Janson SL. Barriers to diabetes management: patient and provider factors. Diabetes Res Clin Pract. 2011;93(1):1-9. http://dx.doi. org/10.1016/j.diabres.2011.02.002. PMid:21382643.

18. Groff DP, Simões WTA, Fagundes ALSC. Adesão ao tratamento dos pacientes diabéticos tipo II usuários da estratégia saúde da família situada no bairro Metropol de Criciúma, SC. Arquivos Catarinesnes de Medicina. Vol 40, 2011.
19. Silvestre Busto C, Ramalle-Gómara E, Arnáez García R, Flor-Serrano A, García-Fernández J, Ramil Pernas $\mathrm{H}$, et al. Multi-centre study of children's adherence to antibiotic treatment in primary care. Aten Primaria. 2001;27(8):554-8. PMid:11412542.

20. Gorter KJ, Tuytel GJ, de Leeuw RR, Bensing JM, Rutten GEHM. Opinion of patients with type 2 diabetes about responsibility, setting targets and willingness to take medication. Patient Educ Couns. 2011;84(1):56-61. http:// dx.doi.org/10.1016/j.pec.2010.06.019. PMid:20655164.

Received: May 09, 2018 Accepted: Nov 11, 2018 